\title{
Cultura e sociedade na primeira Teoria Crítica
}

\author{
Ricardo Musse* \\ https://orcid.org/ 0000-0002-9314-1122
}

A relação entre cultura e sociedade surge como uma questão crucial já no primeiro programa da Teoria Crítica, o discurso de posse de Max Horkheimer na direção do Instituto de Pesquisas Sociais, proferido em 24 de janeiro de 1931. Nele, Horkheimer propõe, como solução para a antinomia entre proposições generalizantes e pesquisa empírica, "uma contínua interpenetração e desenvolvimentos dialéticos entre a teoria filosófica e a prática da ciência particular" (Horkheimer, 1999, p. 128).

Fio condutor da fase inicial do Instituto, o trabalho coletivo de "filósofos, sociólogos, economistas, historiadores, psicólogos” (Horkheimer, 1999, p. 128) tem a incumbência de investigar a "conexão entre a vida econômica da sociedade, o desenvolvimento psíquico dos indivíduos e as transformações que têm lugar nas esferas culturais" (Horkheimer, 1999, p. 130). Horkheimer prescreve que o objeto da primeira pesquisa serão os grupos sociais constituídos por operários qualificados e por empregados do terceiro setor na Alemanha (cf. Horkheimer, 1999, p. 131).

Nesses termos, a elaboração de uma teoria da sociedade exige tanto a consideração da intermediação dos processos psíquicos dos indivíduos, como uma compreensão determinada da cultura. Essa última é definida por Horkheimer, em sentido estrito, como "os assim chamados conteúdos espirituais da ciência, da arte e da religião, mas também o direito, os costumes, a moda, a opinião pública, o esporte, as formas de divertimento, o estilo de vida etc." (Horkheimer, 1999, p. 130).

* Universidade de São Paulo, São Paulo, Brasil. 
No decorrer do texto, Horkheimer refere-se a concepções mais amplas de "cultura”. Distingue, por exemplo, a filosofia social que surge no Idealismo alemão do pensamento filosófico anterior pela sua preocupação com fenômenos que só podem ser entendidos em conexão com a vida social, "com a cultura material e espiritual da humanidade em geral” (Horkheimer, 1999, p. 121).

O conteúdo cultural, cujas transformações o Instituto propõe investigar, situa-se assim num ponto intermediário entre a delimitação hegeliana da esfera cultural constituída pela tríade “arte, religião e filosofia” - e a compreensão antropológica que tende a identificar a cultura com a totalidade social. O recorte que ele privilegia - a apreciação da cultura em sentido estrito - abre caminho para o exame da dinâmica social encetada pelas interconexões entre a produção econômica, os indivíduos e a cultura. Trata-se de uma opção metodológica que combina dimensões próprias da teoria marxista (a consideração da especificidade do modo de produção capitalista), da psicologia social (na vertente inaugurada por Freud) e da tradição sociológica (a relação entre indivíduo e sociedade).

Com a ascensão de Hitler ao poder, em 1933, a pesquisa focada na classe trabalhadora alemã não pôde ser concluída ${ }^{1}$. O projeto inicial assumiu novas feições que resultaram no livro Estudos sobre autoridade e familia $(1935)^{2}$. Na apresentação geral do volume, Horkheimer começa explicitando, em um artigo específico, como concebe o conceito de "cultura". Para tanto, delimita três acepções distintas e complementares do termo (cf. Horkheimer, 1990).

A primeira, apreendida no âmbito da periodização marxista da história, uma Weltgeschichte própria, delimita a cultura como um conjunto de "traços característicos" de uma época. Esses traços constituem para o historiador um índice que permite identificar o período histórico de um evento, de uma instituição ou de uma obra determinada, "da mesma forma que o biógrafo de um sábio ou de um poeta é capaz de estabelecer o momento em que um texto recém-encontrado foi escrito" (Horkheimer, 1990, p. 179).

A determinação da especificidade cultural de uma época, como, por exemplo, a da sociedade capitalista, pressupõe uma segmentação da história humana, a existência de períodos de relativa homogeneidade, que “imprimem sua própria marca não só à

1. Embora os relatos oficiais do Instituto de Pesquisas Sociais (IPS) insistam no caráter inconcluso dessa pesquisa, sabe-se hoje que essa primeira investigação empírica do IPS alcançou dimensões consideráveis. O conjunto do material só teve sua publicação autorizada por Erich Fromm em 1980, não por acaso anos depois do desaparecimento de Theodor Adorno, Max Horkheimer e Herbert Marcuse. Cf. Fromm, 1980.

2. O relato pormenorizado da passagem de uma pesquisa à outra, assim como uma interpretação das continuidades e descontinuidades entre uma e outra podem ser conferidos em Dubiel, 1978. 
atividade econômica, ao direito, à política, à arte, à religião e à filosofia, mas também aos indivíduos" (Horkheimer, 1990, p. 179).

A segunda acepção ressalta o "caráter dinâmico" da cultura. Destaca que, no âmbito de cada período, não se preservam estruturas fixas, antes se operam tendências e contratendências inerentes a um andamento contraditório. A cultura repercute os antagonismos entre as classes sociais e também - decisivos na era do imperialismo entre as nações.

Horkheimer alerta que os ritmos das modificações culturais, históricas e sociais nem sempre estão sintonizados com as transformações na esfera econômica. Exemplifica essa defasagem, a relativa autonomia da cultura, por meio de detalhada exposição dos hábitos então predominantes nas sociedades asiáticas. $\mathrm{Na}$ China ainda persistia, como força paralisante, a "veneração e o culto dos antepassados" (Horkheimer, 1990, pp. 185-186). Apesar de contrariar os interesses materiais dos indivíduos, seu enraizamento na vida psíquica dificultava a penetração das formas econômicas capitalistas e das modalidades de pensamento e ação próprias do mundo moderno.

O conceito de cultura como um processo dinâmico desdobra-se numa terceira acepção. As teorias idealistas e racionalistas da história explicam o funcionamento da sociedade por meio de determinações culturais assentadas na consciência ou na razão. Em contraposição a elas, cabe à concepção materialista destacar que o aparelho psíquico dos indivíduos se organiza por meio de procedimentos de "interiorização, sublimação e complementação da violência física” (Horkheimer, 1990, p. 182).

Responsável pela atribuição de sentido para o sofrimento individual e para o destino coletivo, a cultura tende, em suas explicações, a ocultar a coerção, encobrindo o peso e o papel da violência na vida social. A postura do indivíduo em relação à sociedade - insiste Horkheimer - não pode ser explicada apenas pelo dissenso e conflito entre concepções de mundo: é determinada por gradações de sentimentos de medo e angústia que têm sua matriz no próprio "corpo" dos indivíduos ${ }^{3}$.

Nesse processo, a cultura configura-se como instância de mediação entre o indivíduo e as estruturas de dominação da sociedade. Constitui fator determinante no direcionamento das pulsões, decisivo no desenvolvimento psíquico dos indivíduos. A ambivalência suscitada pelo entrelaçamento das diversas dimensões da cultura, em seus impactos sobre os comportamentos, pode favorecer tanto posições conformistas como críticas, orientando pensamentos, afetos e condutas que apontem "para a conservação ou para a ruptura da ordem social" (Horkheimer, 1990, p. 181).

3. Tratei, de forma mais demorada, dos delineamentos dessa teoria materialista (marxista) de cultura em Musse, 2018. 
A submissão à autoridade, prevalecente na sociedade e na família, indica o grau de dificuldade da luta pela emancipação. No modo de produção capitalista, a capacidade de ação efetiva de indivíduos, grupos e classes depende de um fator específico, da amplitude da reificação. A conjuntura histórica marcada pela emergência de Estados autoritários, segundo Horkheimer, apenas prolonga e intensifica a impotência dos indivíduos diante do mecanismo econômico.

A pseudoindependência dos indivíduos, representada pela filosofia moderna na imagem de uma "mônada” solitária, não aponta para uma proclamada autonomia. Indica antes a subordinação à racionalidade econômica. Nas palavras de Horkheimer, "a mais completa adaptação possível do sujeito à autoridade efetiva da economia é, ao mesmo tempo, a forma da razão na sociedade burguesa” (Horkheimer, 1990, p. 202). Sob a égide da reificação, os impulsos psíquicos e as formas de consciência predominantes no capitalismo, suportes da pretensa "liberdade" do indivíduo abstrato, estão direcionados para a submissão à hierarquia estabelecida, em consonância com a dependência cega à sociedade.

Horkheimer considera a família - descrita como uma instituição "unitária e concreta" (Horkheimer, 1990, p. 236) - como uma instância decisiva na consolidação social da prevalência do princípio da autoridade. Suas modificações históricas, "de unidade de produção em comunidade de consumo", não configuram mais que alterações nas formas e nas bases da dominação paterna.

No capitalismo, em consonância com os mecanismos do fetichismo das mercadorias, a autoridade paterna, assentada no poder monetário, oculta seu caráter de relação social, aparecendo como uma qualidade fixa, naturalizada. A socialização da criança - promovida no interior de um núcleo familiar hierarquizado em termos de mando e obediência - mimetiza a estrutura social, interiorizando a submissão à autoridade, estabelecendo-a como hábito.

Essa tendência geral não é, porém, unívoca. No processo de socialização, a família age tanto de forma deliberada, adotando providências conscientes (à maneira da igreja, da escola, de associações políticas etc.), como por meio de procedimentos não controlados, inerentes à vida pública e privada. Sua importância ímpar, no entanto, advém do fato de que, segundo a teoria freudiana, o rumo do desenvolvimento psíquico dos indivíduos é "determinado pelas relações da criança com os pais, ou seus representantes, e com os irmãos" (Horkheimer, 1990, p. 221). A energia libidinal cristaliza, pela via da repressão e da sublimação e, sobretudo, por meio de configurações específicas do “complexo de Édipo", modalidades distintas de subjetividade, ecoando um espaço de indeterminação e ambivalência presente ou latente no âmbito da cultura.

A pesquisa consolidada no livro Estudos sobre autoridade e família procura averiguar também as modificações então recentes na estrutura e na função da família. 
Trata-se de aferir em que medida a família ainda consiste na principal instância de socialização, no contexto de corrosão acelerada de sua base econômica, de intensificação do desemprego e de emergência de Estados autoritários. A pressão do Estado e da economia monopolizada sobre os laços familiares, o recuo na clivagem entre cultura e produção tendem a inibir a espontaneidade e a autonomia dos indivíduos, pressupostos de um comportamento crítico ${ }^{4}$. A cadência histórica reforça, assim, a pertinência do projeto do Instituto de acompanhar as transformações da relação entre cultura e sociedade.

As investigações propostas e iniciadas por Max Horkheimer foram desdobradas, em vertentes distintas, em dois artigos publicados no volume de 1937 da Revista de Pesquisas Sociais: "Sobre o caráter afirmativo da cultura", de Herbert Marcuse, e "Eduard Fuchs, colecionador e historiador", de Walter Benjamin.

O ensaio de Marcuse estabelece, de antemão, a diferença entre o conceito de "cultura" delineado nos Estudos sobre autoridade e familia e a definição burguesa do mesmo termo. O primeiro debruça-se sobre a totalidade da sociedade, explorando o entrelaçamento do "âmbito espiritual" com o processo histórico de produção e reprodução da vida social. O conceito afirmativo de cultura, por sua vez, considera a cultura como o "reino dos valores e dos fins autênticos" e a contrapõe ao mundo material da necessidade, da utilidade e do trabalho (Marcuse, 1997, p. 95).

A cultura burguesa afirma-se assim como uma esfera, supostamente autônoma, superior ao mundo efetivo da luta diária pela existência. Nesse diapasão, modulados em um tom elevado e solene, a recepção das atividades e dos objetos culturais converte-se em atos de celebração e exaltação, e sua fruição em uma busca de satisfação, parcialmente preenchida por meio da posse de mercadorias 5 .

A determinação da cultura afirmativa mais destacada por Marcuse é seu idealismo. Ao postular a posse de características humanas universais, ela responde "à miséria do corpo com a beleza da alma; à servidão exterior com a liberdade interior, ao egoísmo brutal com o mundo virtuoso do dever" (Marcuse, 1997, p. 98). A cultura se presta assim ao controle das massas insatisfeitas, reconciliando os antagonismos sociais e ocultando a atrofia corporal e psíquica dos indivíduos.

O idealismo da cultura afirmativa, embora tenha suas raízes em Platão e Aristóteles, não se confunde com o idealismo da filosofia clássica alemã. Em seu núcleo

4. Considerações muito pertinentes sobre as determinações da categoria “indivíduo” em Max Horkheimer podem ser encontradas em Wiggershaus, 1998. Na obra do frankfurtiano as páginas que tratam mais explicitamente desse conceito estão no capítulo IV de Eclipse da razão, significativamente intitulado "Ascensão e declínio do indivíduo" (cf. Horkheimer, 2015, pp. 143-178).

5. Alguns desdobramentos da crítica de Marcuse à dimensão solene da cultura podem ser encontrados em Kangussu, 2008. 
encontra-se não o conceito de espírito, mas a ideia de "alma”, assinalando sua estreita "afinidade com o historicismo" (Marcuse, 1997, p. 112).

Segundo Marcuse, a partir do Renascimento estabeleceu-se uma concepção de individualidade apartada e desconectada do processo histórico de desenvolvimento do indivíduo. A ideia de "pessoa" dotada de "alma” obscureceu a sua constituição efetiva a partir de relações sociais ancoradas na forma específica que o trabalho adquiriu no capitalismo, matriz de características como abstração, concorrência e isolamento.

A alma é postulada como uma essência superior e distinta do dispositivo de forças e mecanismos psíquicos, sobrepondo-se ao âmbito da sensibilidade. A busca da felicidade individual é desviada do plano da satisfação e do prazer sensível: "o caráter humano se converte num estado interior" (Marcuse, 1997, p. 103).

O conceito de "alma” glorifica a resignação, "elevando o indivíduo, sem libertá-lo de sua subordinação efetiva” (Marcuse, 1997, p. 103). Mas também, por outro lado, aponta para desejos que não podem ser contemplados no cotidiano da sociedade burguesa; sob sua égide, "o ideal cultural assumiu o anseio por uma vida mais feliz, por qualidades humanas como bondade, alegria, verdade, solidariedade" (Marcuse, 1997, p. 113).

Marcuse destaca, portanto, na cultura burguesa tanto seu caráter afirmativo como seu potencial de negação do existente. Trata-se de uma dialética rarefeita, assentada em um paradoxo singular. $\mathrm{O}$ ideal cultural se constitui como uma dimensão excluída da reificação, relativamente imune às suas determinações; mas justamente por isso incapaz de lhe opor uma resistência efetiva.

A possibilidade de um rompimento privado da reificação é maior no âmbito da arte. No medium da beleza, na esfera estética, "o mundo reaparece como aquilo que é por trás da forma mercadoria: uma paisagem é efetivamente uma paisagem, um homem, efetivamente um homem e uma coisa, efetivamente uma coisa" (Marcuse, 1997, p. 119). A arte proporciona uma satisfação imediata, ausente tanto na filosofia como na religião. Segundo Marcuse, "somente na arte a sociedade burguesa tolerou a realização efetiva de seus ideais, levando-os a sério como exigência universal. Ali se permite o que na realidade dos fatos é considerado utopia, fantasia, rebelião" (Marcuse, 1997, p. 113).

A felicidade propiciada pela arte da cultura afirmativa, porém, além de efêmera, restringe-se ao domínio da vida interior. Ela funciona como um consolo, um alívio para a ausência de liberdade da existência social. A ideia de "alma”, de personalidade, dissimula a debilidade e a atrofia dos indivíduos promovida por uma integração social comandada por forças econômicas.

Na medida em que atribui aos conteúdos da cultura burguesa uma ambivalência estrutural - marcada pelos polos afirmação/negação, contentamento/insatisfação, resignação/crítica, acomodação/rebeldia -, Marcuse a situa como um caso particular do 
conceito dinâmico de cultura, definido por Horkheimer nos Estudos sobre autoridade e familia. $\mathrm{O}$ artigo de Marcuse, contudo, valoriza com maior ênfase as reivindicações da cultura, em especial as da arte burguesa. Esta, enquanto "recordação daquilo que poderia existir", constitui um manancial inestimável para a prática política que tenha por meta saltar "a um mundo totalmente outro" (Marcuse, 1997, p. 99).

Essa situação se altera com a prevalência do capitalismo monopolista e a consolidação do Estado autoritário. A forma da cultura afirmativa se modifica, acompanhando a transição da "mobilização parcial", que ainda preserva a vida privada como uma esfera reservada, para a "mobilização total", exigida e implantada pela nova modalidade de dominação política.

O idealismo cultural da sociedade liberal se reorganiza como "realismo heroico". À primazia da "interiorização", premissa de uma comunidade abstrata assentada em valores universais como liberdade e dignidade, segue-se o primado de uma exteriorização aderente a uma falsa coletividade (de raça, sangue e solo) que exige subserviência, disposição ao sacrifício e ao cumprimento do dever imposto. Essa mutação não prescinde do conceito de "alma". Nas palavras de Marcuse, "o indivíduo provido de alma se submete mais facilmente, se curva mais humildemente ao destino, obedece mais à autoridade" (Marcuse, 1997, p. 125).

A nova mentalidade, atinente à disciplina política autoritária, recusa tanto os princípios da ciência objetiva como a forma artística que busca e assenta seus fundamentos em si própria. A arte é incitada a promover o "culto do Estado" e a "se colocar a serviço da defesa nacional, da disciplina militar e do trabalho" (Marcuse, 1997, p. 126). A despeito desse giro, a cultura afirmativa mantém sua função básica: disciplinar e integrar o indivíduo, cada dia mais amorfo, às novas formas de sociabilidade e de existência da ordem social capitalista.

Em sua obra posterior, Marcuse descreve o processo de autoabolição da cultura afirmativa, salientando sua absorção à lógica da produção mercantil e sua assimilação aos mecanismos de controle próprios da fase monopolista do capitalismo. Constata, porém, a presença de formas artísticas que não se rendem ao pensamento unidimensional. $\mathrm{O}$ modernismo estético, as vanguardas (o surrealismo em especial) não prescindem da "imaginação" e da "fantasia", atividades mentais independentes e antagônicas ao princípio de realidade ${ }^{6}$.

Em Um ensaio para a libertação, livro de 1969, Marcuse considera as afinidades reveladas entre as revoltas da juventude e as vanguardas artísticas como indício

6. A arte como uma possibilidade de contraponto ao pensamento unidimensional, tópico recorrente na obra tardia de Marcuse, é assumida explicitamente na entrevista que ele concedeu a Jürgen Habermas (cf. Habermas, 1968). 
do surgimento de uma nova sensibilidade. Numa (contra)cultura desembaraçada do conceito de "alma", torna-se possível a reabilitação da sensibilidade, a busca da "supremacia dos instintos da vida sobre a agressividade e a culpa" (Marcuse, 1977, p. 40).

A emergência de outras formas de pensar e sentir adquire assim uma dimensão política, num projeto de integração da teoria crítica, da imaginação estética e da práxis humana. Em seu combate ao marxismo tradicional, Marcuse recorre à "tese surrealista que, sem abandonar as premissas materialistas, protesta contra a separação entre o desenvolvimento material e o cultural", advertindo que "a subordinação do último ao primeiro reduz (se é que não nega) as possibilidades libertadoras da revolução" (Marcuse, 1977, p. 51) ${ }^{7}$.

$\mathrm{O}$ apoio de Marcuse às vanguardas não é, no entanto, incondicional. Além de constatar o enfraquecimento de seu pathos de insubmissão e revolta, o déficit de negatividade de seus conteúdos, rejeita seu programa de dissolução, não mediada, da arte na vida. Ele aponta para os riscos de a poética do gesto, a desmaterialização da arte (procedimentos paradigmáticos de uma das vertentes da vanguarda modernista), desembocar na assimilação ao existente, comprometendo o ímpeto transformador da arte ${ }^{8}$.

Em contraposição, Marcuse defende enfaticamente o potencial crítico e utópico da arte autônoma. Num artigo sobre Aragon, ele adverte: "A arte como instrumento de oposição depende da força alienadora da criação estética: de seu poder em permanecer estranha, antagônica, transcendente à normalidade e, ao mesmo tempo, de ser o reservatório das necessidades, faculdades e desejos reprimidos do ser humano, de permanecer mais real do que a realidade cotidiana" (Marcuse, 1999, p. 270).

Sempre atento à presença de germes fascistas na democracia capitalista, Marcuse é mais atual que nunca quando observa - em Contrarrevolução e revolta (1972) - que “o 'fim da arte' é concebível somente quando os seres humanos não são mais capazes de distinguir entre o verdadeiro e o falso, o bom e o mal, o belo e o feio, o presente e o futuro. Isso seria o estado de perfeita barbárie no ápice da civilização - e tal estado é, com certeza, uma possibilidade histórica" (Marcuse, 1973, p. 121).

O ensaio de Walter Benjamin sobre Eduard Fuchs, uma encomenda de Horkheimer entregue três anos depois da solicitação, consolida a aproximação institucional e teórica entre Benjamin e o Instituto. Apesar de afinidades intelectuais e das ami-

\footnotetext{
7. Fredric Jameson, no capítulo de Marxismo e forma dedicado a Marcuse, toma por fio a presença do surrealismo na estética do frankfurtiano (Cf. Jameson, 1985).

8. Os pontos de aproximação e de divergência de Marcuse em relação às ditas "vanguardas estéticas" foram desdobrados, com muita pertinência, em Fabbrini, 2013.
} 
zades pessoais, esse movimento foi marcado, durante muito tempo, por reticências de ambos os lados?.

Não é por acaso, portanto, que a análise do trabalho editorial, da atividade de colecionador e da obra historiográfica de Fuchs - um eminente quadro da social-democracia alemã - constitua apenas o estopim para considerações acerca da relação entre cultura e sociedade. A reflexão sobre essa questão, diretriz apontada no discurso de Horkheimer de 1931, tornou-se efetivamente uma das tarefas prioritárias do Instituto de Pesquisas Sociais.

No início do artigo, Benjamin demarca a linha de sua intervenção no debate. Propõe estabelecer nada mais nada menos que uma "teoria materialista da cultura". Trata-se de um tópico que Marx não julgou premente desenvolver e que passou a ser, assim, uma das lacunas de sua doutrina. O trecho da obra de Marx mais incisivo acerca desse tema, situado no Prefácio a Para a crítica da economia política, afirma que "a estrutura econômica da sociedade [constitui] a base real sobre a qual se ergue uma superestrutura jurídica e política e à qual correspondem determinadas formas sociais de consciência. O modo de produção da vida material condiciona o processo da vida social, política e espiritual” (Marx, 1978, pp. 129-130).

Benjamin considera as interpretações dessa passagem, fixadas por Plekhanov e Mehring, e prevalecentes na social-democracia, muito distantes do espírito da obra de Marx. Ele recorre, como estratégia de combate, a uma peça do arquivo do adversário: uma carta de Engels a Mehring, datada de 15 de julho de 1893. Engels reconstitui aí, num registro mais expandido que a menção ao tema feita por Marx, os fundamentos da crítica à história idealista das ideias delineada em $A$ ideologia alemã, um manuscrito publicado apenas em 1928.

Benjamin destaca, no trecho da carta de Engels citado no artigo, pontos que contestam premissas comuns a diversas vertentes da história das ideias: "o hábito de apresentar um novo dogma como 'evolução' de um anterior [...], a prática de apresentar essas novas constelações separadas de seus efeitos sobre as pessoas e de seu processo de produção, tanto espiritual como econômico. [...] o 'enclausuramento' das várias áreas do saber" (Benjamin, 2012, p. 127).

9. A redação desse artigo, uma demanda postergada por anos, consolida uma relativa e autorreconhecida adesão de Walter Benjamin ao programa de pesquisas delineado por Max Horkheimer em seu discurso de posse na direção do Instituto em janeiro de 1931 (Horkheimer, 1999). A recepção ressalta, em geral, as divergências e polêmicas entre Adorno e Benjamin em torno do caráter da "atenção distraída" da arte pós-aurática, sobre o papel da síntese na dialética e em torno do teor fantasmagórico da mercadoria (um bom roteiro dessas diferenças encontra-se em Gatti, 2009). Por conta desse contencioso - amplificado pela publicação da correspondência entre eles (Adorno, 2012) -, as relações entre Benjamin e Horkheimer permaneceram em segundo plano. 
À primeira vista trata-se apenas de uma retomada de princípios do "materialismo histórico", bastante conhecidos pela geração que teve oportunidade de ler A ideologia alemã. A sutileza da exposição e a terminologia utilizada antecipam, no entanto, o propósito de Benjamin: promover uma crítica da história da cultura, passo inicial para a refundação da teoria materialista da história ${ }^{10}$.

A crítica formulada por Benjamin contesta frontalmente as três tendências então predominantes na historiografia da cultura: o historicismo, o positivismo e o evolucionismo. Ele desaprova no historicismo a atitude contemplativa inerente à construção de uma imagem épica e eterna do passado e seu correlato desapreço pela história da recepção. Em contraposição, a reflexão dialética que se ocupa das formas políticas e jurídicas, da ciência, da arte e da religião, ao liberar cada domínio de seu "enclausuramento", torna a compreensão dos objetos culturais inseparável de sua história prévia e posterior - momentos concebidos como um "processo em permanente transformação" (Benjamin, 2012, p. 128) ${ }^{11}$.

A consideração da recepção da produção cultural modifica sua inserção temporal, a transmissão de seu legado e até mesmo a apreensão de seu teor. Ela ensina, nas palavras de Benjamin, "como a função da obra é capaz de sobreviver ao seu criador e de deixar para trás suas intençôes; como a recepção pelos contemporâneos é parte integrante do efeito que ela exerce sobre nós próprios; e como esse último assenta-se no encontro não apenas com a obra, mas com a história que permitiu que ela chegasse aos nossos dias" (Benjamin, 2012, p. 128).

A relevância da determinação da constelação histórica dos objetos culturais torna-se ainda mais perceptível quando Benjamin examina a historiografia da cultura predominante na social-democracia alemã, uma mescla de positivismo e evolucionismo.

O prestígio concedido às ciências naturais, a associação do ideal de progresso com o desenvolvimento do conhecimento científico e da técnica, contaminou o conceito de história da cultura forjado pela geração de Mehring e Fuchs. Equiparados às descobertas da ciência, os objetos culturais foram apreendidos também como produtos desvinculados da práxis. O programa de "popularização da ciência" do SPD (Partido social-democrata alemão) - tributário de uma visão positivista que "só foi capaz de reconhecer os progressos da ciência, não os retrocessos da sociedade" (Benjamin, 2012, p. 135) - desdobrou-se no esforço de tornar acessível à classe trabalhadora uma cesta de bens culturais.

10. Para um acompanhamento detalhado da relação entre a crítica da história da cultura e o projeto benjaminiano de uma refundação da teoria materialista da história, cf. Chaves, 1998, e Rampim, 2018.

11. Tiedemann mostra como a teoria da história de Benjamin se constituiu como uma crítica de três tendências: historicismo, positivismo, evolucionismo (Cf. Tiedemann, 1987). 
Essa prática, decorrente da elevação da cultura a valor universal, ignora, segundo Benjamin, o caráter dinâmico da cultura e os traços fetichistas, a reificação que transpassa suas obras. A "representação histórica" dos objetos culturais, exposta sob a forma de "homenagem celebratória", encara-os "como independentes, se não do processo que os viu nascer, pelo menos daquele em que sobrevivem. [...] A sua história não seria mais do que os resíduos depositados na consciência dos homens pelas coisas memoráveis, mas desprovidas de experiência autêntica, isto é, política" (Benjamin, 2012, pp. 137-138).

O pressuposto comum a toda historiografia da cultura consiste em posicionar seus objetos em um tempo homogêneo e vazio. O "materialista histórico" (na terminologia recorrente em Benjamin), por sua vez, procura expor as obras no "tempo-de-agora". Não se trata apenas de conceder prioridade ao momento em que os objetos culturais são conhecidos, ao nosso tempo, mas, sobretudo, de apreender a experiência derivada de cada presente como uma "constelação saturada de tensões" (Benjamin, 2012, p. 19).

Os fragmentos do passado surgem aí como mônadas, como imagens dialéticas, resgatando a dimensão política inscrita nos objetos culturais. Constituem assim um elemento essencial para a crítica do presente e para a apreensão de futuros irredutíveis ao futuro que a tradição lhe reserva. A subversão da relação usual entre passado, presente e futuro "arranca a época à continuidade histórica reificada, e assim também a vida à sua época e uma determinada obra ao conjunto de obras de uma vida. Esse procedimento consegue conservar e suprimir na obra a obra de uma vida, na obra de uma vida, a época, e na época, todo o decurso da história" (Benjamin, 2012, pp. 19-20).

A compreensão da história da cultura pela social-democracia tampouco destoa do fundamento teórico da tática política do SPD: a crença determinista em um progresso essencialmente irresistível, percorrendo, por moto próprio, uma trajetória reta. O otimismo geral, a opinião disseminada na classe trabalhadora alemã de que "nadava com a correnteza" (Benjamin, 2012, p. 15), tornou-a cega à perspectiva da barbárie em gestação.

A teoria materialista da cultura, ao contrário, no movimento de se desvencilhar dessa ilusória e falsa consciência se depara com o caráter contraditório dos bens culturais. Segundo a recomendação de Benjamin, um simples olhar distanciado para o passado permite descobrir que "a arte e a ciência têm uma proveniência que não pode ser considerada sem horror. Sua existência se deve não apenas ao esforço dos grandes gênios, seus criadores, mas também à escravidão anônima de seus contemporâneos. Nunca há um documento da cultura que não seja, ao mesmo tempo, um documento da barbárie" (Benjamin, 2012, p. 137). 
Esse trecho do artigo sobre Fuchs é reproduzido literalmente na Tese viI de "Sobre o conceito de história”, com a menção de que tampouco o processo de transmissão desses bens está livre da barbárie ${ }^{12}$. E com a seguinte adição: "Por isso, o materialista histórico, na medida do possível, se afasta dessa transmissão. Ele considera como sua tarefa escovar a história a contrapelo" (Benjamin, 2012, p. 13) ${ }^{13}$.

No mesmo volume da Revista de Pesquisas Sociais em que saíram os artigos de Marcuse e Benjamin, foi publicado também o ensaio “Teoria Tradicional e Teoria Crítica”, de Max Horkheimer, uma espécie de balanço e manifesto do que Habermas denominou posteriormente de "materialismo interdisciplinar" ${ }^{14}$.

$\mathrm{O}$ ensaio institui uma diferença metodológica essencial entre a teoria tradicional e a teoria crítica, aferida a partir do exame da relação entre sujeito, objeto e teoria. Enquanto a teoria tradicional, na esteira da lógica cartesiana, supõe uma invariabilidade entre esses momentos constitutivos da investigação, a teoria crítica, em sintonia com a dialética inerente ao decurso histórico, permanece atenta às transformações da estrutura social e às concomitantes alterações nas configurações da teoria, do sujeito e do objeto.

Horkheimer concebe o sujeito do conhecimento da teoria crítica, seguindo a formulação de Marx em A ideologia alemã, como "um indivíduo determinado em suas relações reais com outros indivíduos e grupos, em seu confronto com determinada classe e, finalmente, no entrelaçamento mediado com a totalidade social e a natureza" (Horkheimer, 1983, p. 132). Sua determinação organiza-se como a exposição de uma série de nexos - numa tessitura que se desdobra por meio da compreensão do objeto, da sociedade que lhe é subjacente -, como uma descrição abreviada da experiência histórica.

Estabelece-se assim uma justificativa para os procedimentos de atualização e ampliação da doutrina marxista, correntes desde a obra do último Engels, mas ainda carentes de fundamentação. Em uma direção específica, Horkheimer busca preservar essa linhagem, em uma época marcada pela contrarrevolução e pela estabilização do capitalismo, situação na qual não se podia mais contar com suas âncoras tradicionais, o proletariado e o partido. Hibernando sob a forma de uma "tradição intelectual", a resistência e a crítica passam a se concentrar na investigação do presente histórico.

O processo de decomposição do "capitalismo liberal”, concorrencial, culminou em sua substituição pelo "capitalismo monopolista”, principal resultado do desen-

12. A continuidade entre o ensaio de W. Benjamin sobre Eduard Fuchs e as Teses "Sobre o conceito de história” é visível na recorrência de conceitos e no aproveitamento de parágrafos inteiros do artigo nas Teses.

13. Para uma leitura atenta dos desdobramentos do lema "escovar a história a contrapelo" cf. Gagnebin, 2014.

14. Jürgen Habermas usa essa expressão em inúmeros momentos de sua obra. Uma determinação sintética do significado dessa categoria pode ser conferida em Habermas, 2015. 
volvimento da técnica e de uma contínua concentração e centralização do capital. Neste, com o predomínio das grandes corporações, os proprietários jurídicos são afastados, e a direção empresarial adquire um poder autônomo que se estende à organização do Estado.

Na nova fase do capitalismo, na emergência de formas diferenciadas de Estado autoritário, Horkheimer identifica alterações substanciais tanto no aparelho jurídico e político como no funcionamento da ideologia. "Com a redução do círculo dos efetivamente poderosos" (Horkheimer, 1983, p. 150), a geração espontânea da ideologia pelo mercado, pelos mecanismos de troca, cede lugar à construção consciente, deliberada.

Nesse cenário, a relação entre cultura e sociedade modifica-se significativamente, até mesmo em seus pormenores. Instância decisiva na mediação entre elas, o indivíduo perde sua autonomia relativa e a capacidade de ter "pensamentos próprios". Nas palavras de Horkheimer:

[... com a destruição do indivíduo típico o conceito de "dependência do cultural" face ao econômico há de ser entendido de modo mais materialista vulgar do que antes, por assim dizer. As explicações dos fenômenos sociais tornaram-se, ao mesmo tempo, mais simples e mais complexas. Mais simples, pois o econômico determina os homens de modo mais imediato e consciente, uma vez que a relativa força de resistência e a substancialidade das esferas culturais estão desaparecendo; mais complexas, pois a dinâmica econômica desenfreada, na qual a maioria dos indivíduos são degradados a meros instrumentos, matura, em ritmo vertiginoso, novas feições e novos infortúnios. (Horkheimer, 1983, p. 151).

Horkheimer retoma essa questão no artigo "Arte e cultura de massa”, redigido em inglês e publicado na revista do Instituto em 1941. Ressalta aí as ameaças à autonomia individual, o encurtamento da distância entre a esfera privada e a ordem social. Segundo ele, "a dissolução gradual da família, a transformação da vida pessoal em lazer e do lazer em rotinas supervisionadas até o último detalhe nos prazeres do cinema e dos parques de diversão, o best-seller e o rádio trouxeram à tona o desaparecimento da vida interior" (Horkheimer, 1941, p. 5).

$\mathrm{Na}$ sociedade de massas, a cultura transforma-se em ocupação do tempo livre. Torna-se um mero apêndice encarregado de revigorar as energias e a disposição dos indivíduos para o trabalho. O tempo consolida-se assim como medida tanto da jornada de trabalho como das horas de folga ${ }^{15}$.

15. Neste artigo usa-se pela primeira vez no âmbito da Escola de Frankfurt a expressão “indústria cultural”. Embora Horkheimer tenha introduzido o conceito, hoje se associa quase automaticamente esse termo 
Essas observações, esparsas e pouco desenvolvidas no artigo, o enquadramento da recepção da cultura como atividade do tempo livre, como fruição por um indivíduo, em processo de aniquilação, de prazeres manipulados, delinearam coordenadas prontamente incorporadas na reflexão da Teoria Crítica. Constituem premissas do conceito de "indústria cultural", desenvolvido, em 1947, na Dialética do esclarecimento, mas também da última conferência pronunciada em vida por Theodor Adorno, em 1969, intitulada justamente "Tempo livre"16.

O fragmento "A indústria cultural: o esclarecimento como mistificação das massas", seguindo a indicação do título, pode ser melhor compreendido observando a confluência de dois movimentos: como um momento da inflexão programática do Instituto, sinalizada em Dialética do esclarecimento, e como uma espécie de atualização, de um reposicionamento acerca da função e do significado da cultura na sociedade de massas.

Adorno e Horkheimer - impactados pelas teses "Sobre o conceito de história", de Walter Benjamin - formulam um diagnóstico do presente por meio de uma constelação conceitual que procura reconstruir as determinações da dominação social ao longo da história. Eles adotam como ponto de partida, em seu esforço para entender a barbárie contemporânea, a seguinte passagem da tese viII: "a tradição dos oprimidos nos ensina que o estado de exceção em que vivemos é a regra”. Dialética do esclarecimento orienta-se por um mote correlato, enunciado no início do livro: "No sentido mais amplo do progresso do pensamento, o esclarecimento tem perseguido sempre o objetivo de livrar os homens do medo e de investi-los na posição de senhores. Mas a terra totalmente esclarecida resplandece sob o signo de uma calamidade triunfal" (Adorno \& Horkheimer, 1985, p. 17).

O "Prefácio" do livro antecipa o nexo específico entre mito e esclarecimento vigente no âmbito da cultura. Nas palavras de Adorno e Horkheimer: "o segmento sobre a indústria cultural mostra a regressão do esclarecimento à ideologia, que encontra no cinema e no rádio sua expressão mais influente. O esclarecimento consiste aí, sobretudo, no cálculo da eficácia e da técnica de produção e difusão. Em conformidade com seu verdadeiro conteúdo, a ideologia se esgota na idolatria do existente e do poder pelo qual a técnica é controlada" (Adorno \& Horkheimer, 1985, p. 15).

à obra de Theodor Adorno. Disseminou-se, inclusive, a lenda, desmentida pela documentação, de que Adorno teria escrito sozinho o excurso da Dialética do esclarecimento intitulado "A indústria cultural. O Esclarecimento como mistificação das massas". Essa distorção talvez se deva ao fato de Adorno, nos anos 1950, ter pronunciado, em Paris, uma conferência sobre o assunto (Adorno, 2021), cuja disseminação mundial popularizou o conceito.

16. Uma análise detalhada desse ensaio, bem como de seu lugar na obra de Theodor W. Adorno, pode ser conferida em Musse, 2016. 
O termo "indústria cultural" designa, portanto, em uma primeira indicação, a forma histórica da cultura predominante na "sociedade de massas". Trata-se de um sistema que articula, a partir de princípios comuns, campos aparentemente distintos como o cinema, o rádio, a televisão, a imprensa e a opinião pública, o esporte, a moda e a publicidade. Adorno e Horkheimer detectam na lógica imanente a cada uma dessas esferas uma surpreendente afinidade com a racionalidade que preside a ciência e a técnica.

A mesma "razão abstrata", subjacente ao processo histórico de dominação da natureza (interna e externa), orienta a totalidade da vida social. Sua prevalência pode ser atestada nas múltiplas dimensões do conceito de "Eu": como homo oeconomicus, como mônada social, como indivíduo reduzido à função mimética, como fundamento metodológico da filosofia e da ciência moderna etc.

As produções artísticas da indústria cultural se diferenciam da arte autônoma e, mesmo, das formas estéticas da cultura afirmativa. No âmbito da indústria cultural, o processo de produção organiza-se, seguindo os ditames da racionalidade técnica e da busca de lucro, por meio de um "esquematismo de procedimentos" - fórmulas prévias geram efeitos premeditados por finalidades impostas pela primazia do valor de troca. Os produtos culturais tornam-se mercadorias no sentido pleno do termo.

A padronização e a produção em série, o planejamento técnico em grande escala e o esquematismo prescrito pelas equipes de produção transformam o caráter e as formas de consumo dos produtos culturais. Sua "constituição objetiva" (Adorno \& Horkheimer, 1985, p. 104) predetermina as modalidades de apreensão e fruição. Com a exigência combinada de atenção e automatismo, com a inibição da atividade intelectual, a imaginação e a espontaneidade do consumidor cultural se atrofiam. Nas palavras de Adorno: "o consumidor não é rei, como a indústria cultural pretende fazer crer, não é sujeito dessa indústria, mas seu objeto" (Adorno, 1986, p. 93) ${ }^{17}$.

A forma artística dos produtos da indústria cultural caracteriza-se por uma "turva identidade" entre o universal e o particular, por um simulacro de harmonia na qual o todo e a parte, intercambiáveis, "exibem os mesmos traços" (Adorno \& Horkheimer, 1985, p. 104). O detalhe, subordinado à totalidade, perde sua independência, torna-se fungível. O estilo da indústria cultural elimina a tensão entre a "regra e a pretensão específica do objeto", "sacrificando o que fazia a diferença entre a lógica da obra e o sistema social” (Adorno \& Horkheimer, 1985, p. 100). Segundo Adorno e Horkheimer, as manifestações artísticas da indústria cultural, conformadas em estrita obediência ao poder e à hierarquia social, bloqueiam a busca

17. Gabriel Cohn examina, com muita pertinência, o papel do sujeito na produção, circulação e consumo das mercadorias culturais, em Cohn, 2017. 
da verdade negativa, a “expressão caótica do sofrimento" (Adorno \& Horkheimer, 1985, p. 107).

A ideologia inscrita nos produtos da indústria cultural "tem por objeto o mundo enquanto tal" (Adorno \& Horkheimer, 1985, p. 122). Desprende-se da exigência de fornecer uma explicação para o significado da vida, de emitir juízos de valor, concentrando-se no "culto do fato". Por conta de um calculado efeito de realidade, encena uma proximidade à vida cotidiana. No "paradoxo da rotina travestida de natureza" (Adorno \& Horkheimer, 1985, p. 106), na "sensação confortável de que o mundo está em ordem" (Adorno, 1986, p. 99), consuma-se - mesmo sob o rótulo de "novo" - a reprodução do sempre igual. Assim, dizem Adorno e Horkheimer, a indústria cultural "se converte na proclamação enfática e sistemática do existente" (Adorno \& Horkheimer, 1985, p. 122).

Em simbiose, intercambiam técnicas de engodo e compartilham interesses econômicos. No auge do capitalismo monopolista, a propaganda perde seu teor informativo, apêndice necessário à troca mercantil, e torna-se mero reclame da marca, consolidando, por meio de seus slogans, "os grilhões que encadeiam os consumidores às grandes corporações” (Adorno \& Horkheimer, 1985, p. 134). A indústria cultural, de forma análoga, transita entre a autopromoção e a afirmação do poderio social.

O impacto da indústria cultural sobre a subjetividade corrobora a trajetória regressiva do processo de individuação. Como atividade do tempo livre, reitera e complementa a alienação inscrita na organização capitalista do trabalho. Como forma histórica da cultura predominante no "mundo administrado", a indústria cultural constitui uma das instâncias de socialização, de formatação reificada da consciência e do inconsciente dos indivíduos ${ }^{18}$. Dispensado do esforço de individuação, seu consumidor é descrito na Dialética do esclarecimento como o protótipo da "pseudoindividualidade”. Designa-se com esse termo o caráter fictício dos indivíduos, reduzidos a "mera encruzilhada das tendências" predominantes na "aparelhagem econômica e social" (Adorno \& Horkheimer, 1985, p. 128).

$\mathrm{Na}$ dialética entre as duas faces do esclarecimento, a autopreservação e a emancipação, a indústria cultural, unidimensional, ocupa apenas o polo que reafirma e reforça o existente. Daí o veredicto de Adorno e Horkheimer: "A barbárie estética consuma hoje a ameaça que sempre pairou sobre as criações do espírito desde que

18. Depois do desfecho da Segunda Guerra Mundial - e, sobretudo, a partir de 1947 com o início da Guerra Fria -, Theodor Adorno passa a usar o conceito de "mundo administrado" em lugar de "capitalismo monopolista" ou "capitalismo de Estado". Essa escolha indica a divergência de Adorno em relação à conceitualização de Franz Neumann e Frederic Pollock, mas também procura ressaltar as identidades de fundo entre os dois blocos antagônicos. 
foram reunidas e neutralizadas a título de cultura. Falar em cultura sempre foi contrário à cultura. $\mathrm{O}$ denominador comum 'cultura' já contém virtualmente o levantamento estatístico, a catalogação, a classificação que introduz a cultura no domínio da administração" (Adorno \& Horkheimer, 1985, p. 108).

Os temas desse parágrafo foram desdobrados por Adorno, implícita ou explicitamente, em uma série de artigos publicados nas décadas de 1950 e 1960. A exposição das determinações atinentes à dialética entre cultura e administração conduziu Adorno a redimensionar os dois conceitos, destacando suas conexões.

Em um artigo de 1960 denominado justamente "Cultura e administração", ele retoma, em chave crítica, o conceito usual de cultura. Segundo ele, a atribuição de um mesmo nome, cultura, à reunião de esferas díspares como filosofia e religião, ciência e arte, formas de vida e costumes, ao espírito objetivo de uma época, denuncia o olhar administrativo, o afã de tudo classificar e organizar a partir de uma perspectiva externa. Trata-se de uma antinomia, pois o específico da cultura é seu descolamento do processo de reprodução da vida material. Adorno reconhece ainda que não é possível estabelecer uma definição precisa do termo. Nessa, por exemplo, estão excluídas as esferas do direito e da política e, nas atuais circunstâncias históricas, até mesmo as ciências naturais.

Adorno desdobra o conceito de "administração" a partir de uma análise crítica da "sociologia da burocracia" de Max Weber. Adorno considera, em linhas gerais, que fenômenos como a superação das formas tradicionais de gerenciamento, a autonomia do aparato organizacional, sua expansão para além da esfera estatal, não podem ser explicados apenas pela superioridade técnica dos modernos procedimentos administrativos. O funcionamento da organização segundo uma lógica própria, à maneira de um "sujeito automático", não pode ser compreendido ignorando o fato de que a relação de troca, no capitalismo monopolista, abrange a totalidade da vida social. A reificação, o pensar em equivalentes, a comensurabilidade entre os objetos constituem o fundamento da redução das diferenças entre os setores e dentro de cada um, viabilizando a eficácia de regras abstratas e reduzindo assim as resistências à planificação e à administração.

Sob a égide da racionalidade administrativa, a cultura é avaliada de forma heterônoma, segundo normas e padrões abstratos e universais que subsumem o particular, desconsiderando seus aspectos qualitativos e seu protesto frente ao universal. A cultura é submetida assim a um processo de naturalização e uniformização, consolidando sua tendência a apartar-se, sem fissuras, do mecanismo social e da práxis possível.

Adorno alerta ainda que a razão administradora não opera apenas como uma instância externa. Ela afeta o âmago dos produtos culturais, pois sequer seus criadores escapam da crescente "composição orgânica dos seres humanos" (Adorno, 2020, 
p. 261), do predomínio do aparato sobre a espontaneidade. Ele indica como sinal da neutralização do cultural o fomento por instituições oficiais de manifestações artísticas contestadoras que, com frequência, denunciam o institucional. Ressalta também a presença disfarçada de categorias administrativas em produtos da arte autônoma e da vanguarda.

A sociedade administrada intensifica, assim, a negação do próprio conceito de cultura. Seus elementos constituintes tendem a ser cancelados. A autonomia desaparece quando o sujeito abdica do poder de formular as regras internas do objeto, atendendo à exigência de seguir o previamente estipulado. A espontaneidade declina; a planificação do todo prevalece sobre a experiência e a emoção individual. A crítica passa a ser considerada como um comportamento antiquado, sendo substituída, sem percalços, pela "informação".

Nesse artigo, Adorno não se furta à tarefa de propor recomendações para a política cultural, sugestões acerca do que fazer aqui e agora. Paradoxalmente, atribui um potencial crítico àquilo que designa como "o mais questionável no mundo administrado, o funcionamento autossuficiente das instâncias executivas" (Adorno, 2020, p. 272). Descortina aí a possibilidade de uma administração cultural, informada por uma reflexão crítica, que se empenhe em "absorver no planejamento o não planejado, o espontâneo" (p. 268). A criação de "espaços de liberdade”, de refúgios que permitam salvaguardar a cultura dos ditames do mercado e de governos autoritários, não prescinde do apoio de experts, de intelectuais aptos a representar os interesses do público contra a opinião pública.

Adorno conclui o artigo afirmando que, apesar da reificação inerente à "cultura" e à "administração",

[...] ambas não o são totalmente, tal como ainda a mais venturosa maquinaria cibernética, ambas remetem a sujeitos vivos. Por ora, na ordem democrático-liberal. Mas também nas instituições e com seu auxílio, o indivíduo ainda tem espaço suficiente para contribuir um pouco para sua correção. Quem quer que opere os meios administrativos e as instituições com imperturbável senso crítico pode ainda realizar algo mais que a pura cultura administrada. As mínimas diferenças no sempre igual, que lhes permanecem abertas, representam, ainda que frágeis, uma possibilidade de diferença em relação ao todo; na própria diferença, na divergência, se concentra a esperança (Adorno, 2020, 273).

Não se trata, porém, de um atributo exclusivo de uma categoria profissional determinada, mas de uma perspectiva aberta à ação de todos. Os artigos e, sobretudo, as intervenções públicas de Adorno (muitas delas recolhidas em livros) seguem uma diretriz indicada em Minima moralia ([1951] 2008) e desdobrada no ensaio "Notas 
marginais sobre teoria e práxis", de 1969: ante a possibilidade "extremamente limitada" de alteração dos fundamentos objetivos da sociedade administrada, as formas de resistência, as práticas concretas - no empenho de fortalecer a autonomia do indivíduo - devem conceder prioridade à dimensão subjetiva. Numa situação em que a impotência, a apatia e o imobilismo se encontram disseminados, o âmbito da cultura constitui um campo de forças decisivo para o esforço de evitar a integração plena da consciência e as tendências regressivas que estão na raiz da barbárie.

\section{Referências bibliográficas}

Adorno, Theodor. (1986), “A indústria cultural”. In: CoHn, Gabriel (org.). Sociologia. 3 ed. Tradução de Amélia Cohn e Gabriel Cohn. São Paulo, Ática, pp. 92-99.

Adorno, Theodor. ([1969] 1995a), "Notas marginais sobre teoria e práxis”. In: Adorno,

Theodor. Palavras e sinais. Modelos criticos II. Tradução de Maria Helena Ruschel. Supervisão de Álvaro Valls. Petrópolis, Vozes, pp. 202-229.

Adorno, Theodor. ([1969] 1995b), “Tempo livre”. In: Adorno, Theodor. Palavras e sinais. Modelos críticos II. Tradução de Maria Helena Ruschel. Supervisão de Álvaro Valls. Petrópolis, Vozes, pp. 70-82.

Adorno, Theodor. ([1951] 2008), Minima moralia. Tradução de Gabriel Cohn. Rio de Janeiro, Azougue.

Adorno, Theodor. (2012), Correspondência 1928-1940 Adorno-Benjamin. Tradução de José Marcos Mariani de Macedo. São Paulo, Unesp.

Adorno, Theodor. (2020), “Cultura e administração". In: Adorno, Theodor. Indústria cultural. Tradução de Vinicius Marques Pastorelli. São Paulo, Unesp, pp. 241-273.

Adorno, Theodor. (2021), "Resumé sobre indústria cultural". In: Adorno, Theodor. Sem diretriz: parva aesthetica. Tradução de Luciano Gatti. São Paulo, Unesp, pp. 45-59.

Adorno, Theodor \& Horkheimer, Max. (1985), Dialética do esclarecimento: fragmentos filosóficos. Tradução de Guido A. de Almeida. Rio de Janeiro, Zahar.

Benjamin, Walter. ([1937] 2012), "Eduard Fuchs, colecionador e historiador”. In: BenjAMIN, Walter. $O$ anjo da história. Tradução de João Barrento. Belo Horizonte, Autêntica, pp. 123-164.

Benjamin, Walter. (2012), "Sobre o conceito da História”. In: Benjamin, Walter. O anjo da história. Tradução de João Barrento. Belo Horizonte, Autêntica, pp. 7-20.

Chaves, Ernani. (1998), "É possível uma história materialista da cultura? Walter Benjamin (re)lê Friedrich Engels". In: Loureiro, Isabel \& Musse, Ricardo (orgs.). Capitulos do marxismo ocidental. São Paulo, Unesp, pp. 59-75. 
Corn, Gabriel. (2017), “As duas faces da indústria cultural”. In: CoHn, Gabriel. Weber, Frankfurt. Teoria e pensamento social I. Rio de Janeiro, Azougue, pp. 239-255.

Dubiel, Helmut. (1978), Wissenschaftsorganisation und politische Erfahrung: Studien zur frühen Kritischen Theorie. Frankfurt am Main, Suhrkamp.

Fromm, Erich. (1980), Arbeiter und Angestellte am Vorabend des Dritten Reiches. Eine Sozialpsychologische Untersuchung. Stuttgart, Deutsche Verlags-Anstalt.

FABBRINI, Ricardo. (2013), "Marcuse e a modernidade artística”. In: Bretas, Aléxia Cruz. Do romance de artista à permanência da arte: Marcuse e as aporias da modernidade estética. São Paulo, Annablume, pp. 11-25.

Gagnebin, Jeanne Marie. (2014), “Estética e experiência histórica em Walter Benjamin”. In: GaGnebin, Jeanne Marie. Limiar, aura e rememoração. Ensaios sobre Walter Benjamin. São Paulo, Editora 34, pp. 197-216.

Gatti, Luciano. (2009), Constelações: crítica e verdade em Benjamin e Adorno. São Paulo, Edições Loyola.

Habermas, Jürgen (org.). (1968), Antworten auf Herbert Marcuse. Frankfurt am Main, Suhrkamp.

Habermas, Jürgen. (2015), “Max Horkheimer: sobre a história do desenvolvimento de sua obra”. In: Habermas, Jürgen. Textos e contextos. Tradução de Antonio Ianni Segatto. São Paulo, Unesp, pp. 143-168.

Horkheimer, Max. (1941), "Art and mass culture". Zeitschift für Sozialforschung, Jahrgang 9. München, DTV reprint, pp. 290-304.

Horkheimer, Max. ([1936] 1983), Autoridade e família. Tradução de Manuela R. Sanches, Teresa R. Cadete. Lisboa, Apáginastantas.

Horkheimer, Max. (1983), “Teoria Tradicional e Teoria Crítica”. In: Benjamin, Walter; Horkheimer, Max; Adorno, Theodor W. \& Habermas, Jürgen. Textos escolbidos. Tradução de José Lino Grünnewald. São Paulo, Abril Cultural, pp. 117-154.

Horkheimer, Max. (1990), “Autoridade e família”. In: Horkheimer, Max. Teoria critica I. Tradução de Hilde Cohn. São Paulo, Perspectiva, pp. 175-236.

Horkheimer, Max. (1999), "A presente situação da filosofia social e as tarefas de um Instituto de Pesquisas Sociais". Revista Praga, n. 7. São Paulo, Hucitec, pp. 121-132.

Horkheimer, Max. (2015), Eclipse da razão. Tradução de C. H. Pissardo. São Paulo, Unesp. JAMESON, Fredric. (1985), “Marcuse e Schiller”. In: JAMESON, Fredric. Marxismo e forma. Teorias dialéticas da literatura no século XX. Tradução de Iumna Maria Simon (coordenação), Ismail Xavier, Fernando Oliboni. São Paulo, Hucitec, pp. 70-93.

Kangussu, Imaculada. (2008), Leis da liberdade. A relação ente estética e política na obra de Herbert Marcuse. São Paulo, Loyola.

Marcuse, Herbert. (1973), Contrarrevolução e revolta. Tradução de Álvaro Cabral. Rio de Janeiro, Zahar. 
Marcuse, Herbert. ([1969] 1977), Um ensaio para a libertação. Tradução de Maria Ondina Braga. Lisboa, Bertrand.

Marcuse, Herbert. (1997). "Sobre o caráter afirmativo da cultura”. In: Cultura e sociedade I. Tradução de Wolfgang Leo Maar, Isabel Maria Loureiro, Robespierre de Oliveira. São Paulo, Paz e Terra, pp. 89-136.

Marcuse, Herbert. (1999), "Algumas considerações sobre Aragon: arte e política na era totalitária”. In: MARCuse, Herbert. Tecnologia, guerra e fascismo. Organização de Douglas Kellner; tradução de Maria Cristina Vidal Borba. São Paulo, Unesp, pp. 267-288.

MarX, Karl. ([1857] 1978), Para a crítica da economia política. São Paulo, Abril Cultural.

Marx, Karl. ([1845-1846] 1986), A ideologia alemã. São Paulo, Hucitec.

Musse, Ricardo. (2016), “A administração do tempo livre”. Lua Nova, São Paulo, Cedec, 99: 107-134.

Musse, Ricardo. (2018) “Max Horkheimer: a teoria da autoridade”. In: SGanzerla, Anor; VAlverde, Antonio José Romera \& Falabretti, Ericson (orgs.). O pensamento politico em movimento. Curitiba, PucPress, 2018, pp. 217-228.

RAMPim, João Lopes. (2018), Colecionador, arte e materialismo histórico em Walter Benjamin. São Paulo, Unifesp.

Tiedemann, Rolf. (1987), Études sur philosophie de Walter Benjamin. Paris, Actes du Sud. Wiggershaus, Rolf. (1998), Max Horkheimer zur Einführung. Hamburgo, Junius.

\section{Resumo}

Cultura e sociedade na primeira Teoria Crítica

A questão acerca da relação entre cultura e sociedade constitui um dos temas centrais da primeira geração da Teoria Crítica, num percurso que se estende do discurso de posse de Max Horkheimer na direção do Instituto de Pesquisas Sociais aos últimos textos de Adorno. Este artigo se propõe a acompanhar a questão ao longo dessa trajetória. Para tanto, concentra-se no comentário de alguns conceitos decisivos: cultura, autoridade e família; cultura afirmativa; teoria materialista da cultura; indústria cultural e cultura no mundo administrado.

Palavras-chave: Teoria crítica; Indústria cultural; Cultura e administração; Teoria materialista da cultura; Cultura afirmativa. 


\section{Abstract}

\section{Culture and society in the first Critical Theory}

The question of the relationship between culture and society is one of the central themes of the first generation of Critical Theory, it extends from possession speech of Max Horkheimer at the Institute of Social Research to Adorno's last texts. This article aims to follow the issue along this trajectory. To this end, it focuses on commenting on some decisive concepts: culture, authority and family; affirmative culture; materialist theory of culture; cultural industry and culture in the administered world.

Keywords: Critical Theory; Cultural industry; Culture and administration; Materialist theory of culture; Affirmative culture.

Texto recebido em 22/01/2021 e aprovado em 12/02/2021.

DOI: 10.11606/0103-2070.ts.2021.181238.

Ricardo Musse é professor do Departamento de Sociologia da Universidade de São Paulo (USP).E-mail: rmusse@usp.br. 